\title{
[5]Rotaxane and [5]Pseudorotaxane Based on Cucurbit[6]uril and Anchored to a Meso-tetraphenyl Porphyrin
}

\author{
DÖNÜS TUNCEL*, NESIBE CINDIR and ÜNSAL KOLDEMIR \\ Chemistry Department, Bilkent University, 06800, Ankara, Turkey
}

(Received: 31 October 2005; in final form: 14 March 2006)

\begin{abstract}
Water soluble [5]rotaxane and [5]pseudorotaxane based on cucurbit[6]uril and anchored to a meso-tetraphenyl porphyrin have been synthesized and characterized by spectroscopic methods $\left({ }^{1} \mathrm{H}-\mathrm{NMR},{ }^{13} \mathrm{C}-\mathrm{NMR}\right.$ and UV), and by elemental analysis, and mass spectrometry. The preliminary results of the pH-driven switching properties of [5]rotaxane investigated through ${ }^{1} \mathrm{H}-\mathrm{NMR}$ spectroscopy are reported. These results were compared with those obtained from a model porphyrin, which was prepared by the de-threading cucurbit[6]uril from [5]pseudorotaxane under basic conditions.
\end{abstract}

\section{Introduction}

The construction of nanometer-scale devices and machines is one of the prime goals for the near future nano-technological progress [1]. For this purpose, (pseudo)rotaxanes have been designed and synthesized; these are compounds which respond to external stimuli, be it chemical, electrochemical or photochemical, by changing their shape or by switching processes or movements [2]. Cyclodextrin, crown ethers, cyclophanes, and calixarenes are the most widely used macrocyles [2, 3], but recently cucurbit[6]uril [4] and its homologues [4c] have joined this list as macrocycles in the synthesis of (pseudo)rotaxanes, and (pseudo)polyrotaxanes [4, 5].

This multi functional hexameric macrocycle, cucurbit[6]uril, comprises a hydrophobic interior with two identical hydrophilic portals, and is synthesized from an acid-catalyzed condensation reaction of glycoluril and formaldehyde $[4,5]$. Its ability to encapsulate protonated diaminoalkanes along with its $\mathrm{pH}$-dependent binding interactions have been used to design molecular switches and pseudopolyrotaxanes [4a,b, 5, 6]. Moreover, this macrocycle can catalyze 1,3-dipolar cycloaddition. This characteristic has also been used to prepare rotaxanes and polyrotaxanes successfully [4a, 5].

In a rotaxane which is designed to function as a molecular switch, the shuttling of the macrocycle under an external stimulus from one location to the other within the molecule can be monitored by spectroscopic methods; this would be mainly through NMR spectroscopy but UV-Vis spectroscopy can also be used if an appropriate chromophore is incorporated in the molecule $[3,6]$.

* Author for correspondence. E-mail: dtuncel@ fen.bilkent.edu.tr
In this work, porphyrin has been selected as the chromophore due to its interesting spectroscopic properties; it also has potential applications in the areas of artificial photosynthesis and molecular photonics [7]. Furthermore, anionic and cationic water soluble porphyrins have a particular importance in biology and photodynamic therapy [8]. However, their tendency to form aggregates in water is undesirable in some applications. A number of different approaches to circumvent this problem have been reported. These methods include the encapsulation of porphyrin with a suitable macrocycle. To this end, (pseudo)rotaxanes based on cyclodextrin and calixaranes were synthesized; these can mimic heme-containing proteins [9]. To the best of our knowledge, there are no studies of porphyrin containing rotaxanes based on cucurbit[n]uril in aqueous media.

Herein we are reporting the synthesis and characterization of water soluble [5]pseudorotaxane, and [5]rotaxane anchored to a meso-tetraphenyl porphyrin, based on cucurbit[6]uril. The preliminary results of the pH-driven switching properties of the [5]rotaxane investigated through ${ }^{1} \mathrm{H}-\mathrm{NMR}$ spectroscopy will also be discussed by comparing the results with those obtained from a model porphyrin prepared by de-threading cucurbit[6]uril from [5]pseudorotaxane.

\section{Results and discussion}

Cucurbit[6] uril 1 was synthesized as previously reported [5]. [5]Rotaxane 4b and [5]pseudorotaxane 4a were synthesized according to Scheme 1. To synthesize the propargylic porphyrin 3, the precursor porphyrin 2 [10] was treated with excess propargylamine to prevent the overalkylation.

After the necessary work-up, porphyrin 3 was purified by column chromatography and the resulting purple 


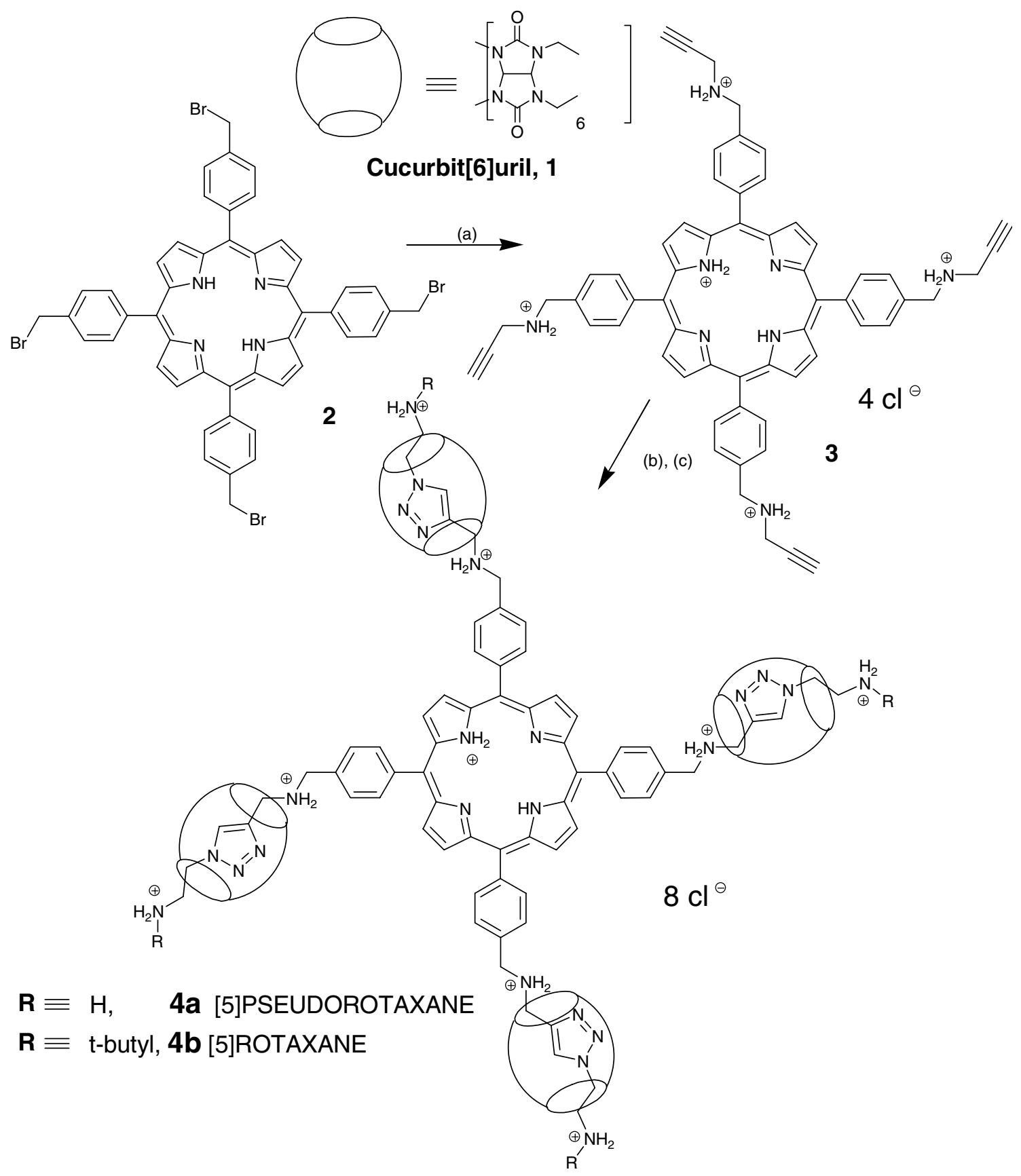

Scheme 1. Syntheses of [5]pseudorotaxane $\mathbf{4 a}$ and [5]rotaxane $\mathbf{4 b}$. Reactants and reaction conditions: (a) Excess, 50 fold, propargylamine, $\mathrm{CH}_{2} \mathrm{Cl}_{2}, \mathrm{rt}, 72 \mathrm{~h} ; 0.1 \mathrm{~N} \mathrm{HCl}, \mathrm{CH}_{2} \mathrm{Cl}_{2}, \mathrm{rt}, 8 \mathrm{~h}, 80 \%$. (b) Synthesis of $4 \mathrm{a}: 4$ equiv. 1, 4 equiv. $\mathrm{H}_{2} \mathrm{NCH}_{2} \mathrm{CH}_{2} \mathrm{~N}_{3} \cdot \mathrm{HCl}, 6 \mathrm{~N} \mathrm{HCl}, 48 \mathrm{~h}, \mathrm{rt}, 75 \%$. (c) Synthesis of $\mathbf{4 b}$ : 4 equiv. 1, 4 equiv. $t$-butyl- $\mathrm{HNCH}_{2} \mathrm{CH}_{2} \mathrm{~N}_{3} \cdot \mathrm{HCl}, 6 \mathrm{~N} \mathrm{HCl}, 48 \mathrm{~h}, \mathrm{rt}, 85 \%$.

colored solid was converted to its hydrochloride salt by dissolving in $0.1 \mathrm{~N}$ aqueous $\mathrm{HCl}$. Subsequently, the salt was recrystallized from water-acetone to give the protonated porphyrin 3 in $80 \%$ yield. For a typical synthesis of a rotaxane, one equiv. porphyrin $\mathbf{3}$ and four equiv. tert-butyl azidoethylammonium chloride were dissolved in water and added to the solution of 4.1 equiv. 1 in $6 \mathrm{~N}$ aqueous $\mathrm{HCl}$ solution. After stirring for $48 \mathrm{~h}$ at $\mathrm{rt}$, the solvent was removed under reduced pressure and the green solid was suspended in hot water to remove unreacted 1 by membrane filtration $(0.45 \mu \mathrm{m}$ pore diameter). The filtrate was concentrated and precipitated into an ethanol-acetone mixture. [5]Rotaxane $\mathbf{4 b}$ and [5]pseudorotaxane $\mathbf{4 a}$ were obtained in $85 \%$ and $75 \%$ yields respectively.

Porphyrin monomer 3, [5]rotaxane $\mathbf{4 b}$ and [5]pseudorotaxane 4a were fully characterized through ${ }^{1} \mathrm{H},{ }^{13} \mathrm{C}$ NMR, UV-Vis spectroscopies, elemental analysis and mass spectrometry (supporting information). MALDITOF mass spectrometry supplied strong evidence for the formation of $\mathbf{4 a}$ and $\mathbf{4 b}$.

${ }^{1}$ H-NMR spectra also confirm the formation of $\mathbf{4 a}$ and $\mathbf{4 b}$, which is evident from the appearance of a chemical shift at $6.6 \mathrm{ppm}$ due to the proton of an encapsulated triazole ring formed through 1,3-dipolar cycloaddition catalyzed by $\mathbf{1}$ as reported in the literature 
[5], as well as the disappearance of the chemical shift at around $3.2 \mathrm{ppm}$ for the terminal proton of the alkyne group of 3. Furthermore, upon the formation of $\mathbf{4 a}$ and $\mathbf{4 b}$, there is a significant downfield shift $(0.3 \mathrm{ppm})$, due to the phenyl proton $\mathbf{c}$ (Scheme 2) of porphyrin, relative to the chemical shift before rotaxane formation. The structures of $\mathbf{4 a}$ and $\mathbf{4 b}$ were further verified by using the integral of phenyl protons and $\beta$-pyrrole protons and comparing them to the integral for the triazole proton. The expected ratio of $2+2+1$ (phenyl + pyrrole + triazole) was found in both cases.

After the preparation of [5] rotaxane $\mathbf{4 b}$, we set out to investigate the $\mathrm{pH}$ dependent switching processes of $\mathbf{4 b}$ through ${ }^{1} \mathrm{H}-\mathrm{NMR}$ spectroscopy. The proposed $\mathrm{pH}$ dependent switching processes of $\mathbf{4 b}$ were depicted in Scheme 2. There are two recognition sites in this system: diaminotriazole and benzylamine. It is known from Mock's extensive studies on the complexation of cucurbit[6]uril with organic molecules that the largest molecule which $\mathbf{1}$ can encapsulate is the para substituted benzene ring [11]. For this reason, the size of the para substituted phenyl and triazole species are appropriate to bind within the cavity of $\mathbf{1}$. When all the nitrogen atoms of $t$-butylamine and the benzylamine groups of $\mathbf{4 b}$ are protonated, cucurbit[6]uril prefers to encapsulate the protonated diaminotriazole site (we call this state I). This is accomplished by the formation of a stable inclusion complex through two ion-dipole interactions between ammonium ions of $t$-butyl and benzyl, and the carbonyl oxygens at the portals of $\mathbf{1}$. However, when the nitrogen atoms of benzylammonium group begin to deprotonate, switching would be intermediate (state II) with some cucurbit[6]uril shifted over the phenyl rings. On the other hand, if the remaining ion-dipole interaction is disrupted by the deprotonation of terminal ammonium ions, 1 will probably reside mostly on the relatively more hydrophobic benzyl part, where the resulting inclusion complex can be better stabilized by hydrophobic effect (state III) (Scheme 2).

First, in order to prove the proposed switching process, and to compare the $\mathrm{pH}$ dependent ${ }^{1} \mathrm{H}-\mathrm{NMR}$ spectral changes which would take place during switching, a cucurbit[6]uril-free model compound, porphyrin $\mathbf{5}$, which is the dumbbell of $\mathbf{4 a}$, was prepared by de-threading 1 from [5]pseudorotaxane $\mathbf{4 a}$ under basic conditions $(\mathrm{pH}>12)$ as shown in Scheme 3. The dumbbell of $\mathbf{4 a}$ rather than $\mathbf{4 b}$ was selected as a model porphyrin, because it is easier to de-thread $\mathbf{1}$ from the former since it does not contain a stopper group. Figure 1a shows the ${ }^{1} \mathrm{H}-\mathrm{NMR}$ spectrum of porphyrin $\mathbf{5}$. As shown in the ${ }^{1} \mathrm{H}-\mathrm{NMR}$ spectrum of $\mathbf{5}$ (Figure 1a), in the absence of $\mathbf{1}$, the resonance due to the triazole proton is shifted downfield (ca. $1.7 \mathrm{ppm}$ ).

In order to observe the $\mathrm{pH}$ dependent ${ }^{1} \mathrm{H}-\mathrm{NMR}$ spectral changes in 5, NMR spectra of $5(2.0 \mathrm{mM})$ in $\mathrm{D}_{2} \mathrm{O}$ were recorded at intervals while raising the $\mathrm{pH}$ using triethylamine (TEA) as a base. Up to $\mathrm{pH} 6.5$, no significant changes in the chemical shifts were observed. Around $\mathrm{pH} 6.5$ as shown in Figure 2b, the spectrum revealed up-field shifts due to phenyl protons c $(\sim 0.4 \mathrm{ppm})$ and $\mathbf{b}(\sim 0.2 \mathrm{ppm})$; these up-field shifts may be attributable to the deprotonation of pyrrole nitrogens of porphyrin. By raising the $\mathrm{pH}$ of the solution to $7,{ }^{1} \mathrm{H}-$ NMR spectrum was recorded (Figure 1c). However, only minor changes in the resonances of phenyl protons were observed. It is not possible to raise the $\mathrm{pH}$ of the solution further because porphyrin 5 undergoes precipitation beyond $\mathrm{pH}$ 7. Probably at this $\mathrm{pH}$, the nitrogen atoms of the benzylammonium ions begin to deprotonate, and the porphyrin-porphyrin interaction results in aggregate formations.

After the $\mathrm{pH}$ dependent ${ }^{1} \mathrm{H}-\mathrm{NMR}$ spectral changes of model porphyrin $\mathbf{5}$ were investigated, ${ }^{1} \mathrm{H}-\mathrm{NMR}$ spectra of $\mathbf{4 b}$ in $\mathrm{D}_{2} \mathrm{O}$ were measured as a function of $\mathrm{pH}$ to explore the switching processes of $\mathbf{1}$, (Figure 2).

When $\mathbf{4 b}$ is dissolved in $\mathrm{D}_{2} \mathrm{O}$ at a concentration of $2.0 \mathrm{mM}$, the color of the solution is green and its $\mathrm{pH}$ is 3.5 (Figure 2a). At this $\mathrm{pH}$, pyrrole nitrogens of porphyrin are protonated, judging from the green color and the UV-Vis data [12] (supporting information). However, after the addition of TEA $(\mathrm{pH} \sim 4)$, the solution turns red, indicating the deprotonation of pyrrole

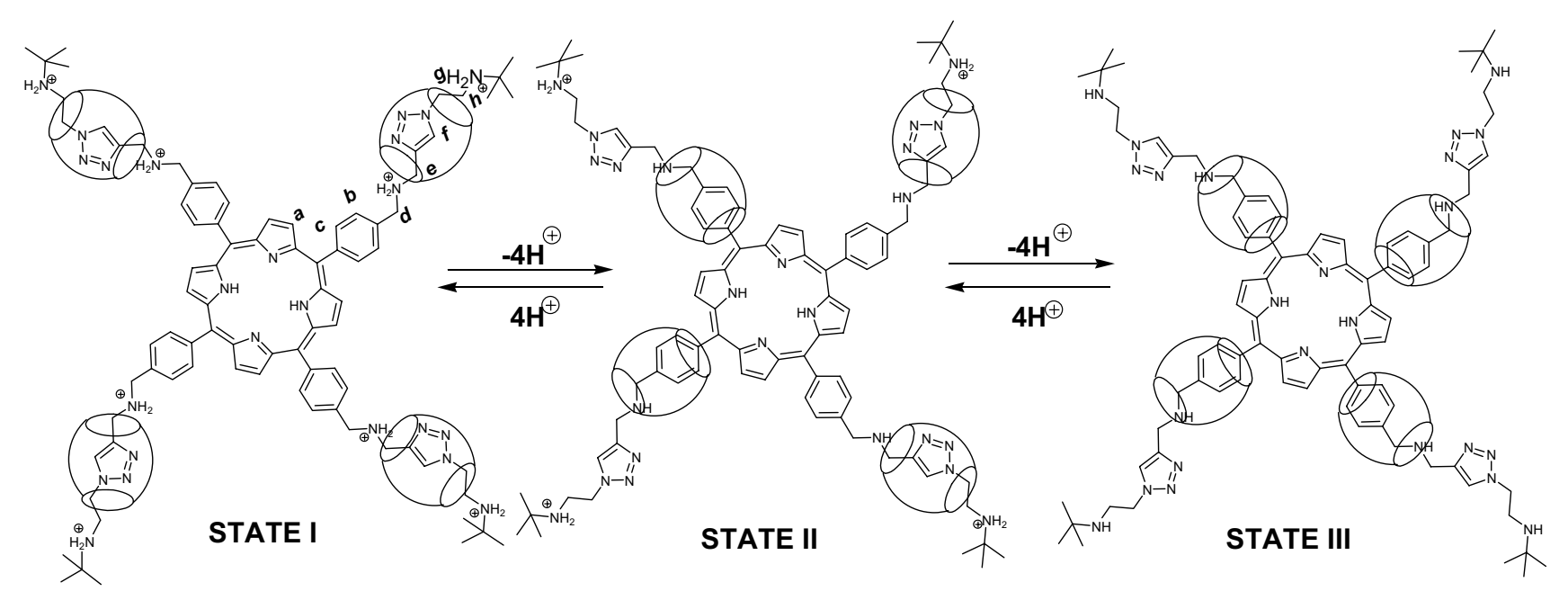

Scheme 2. Proposed $\mathrm{pH}$ dependent switching process of $\mathbf{4 b}$. 


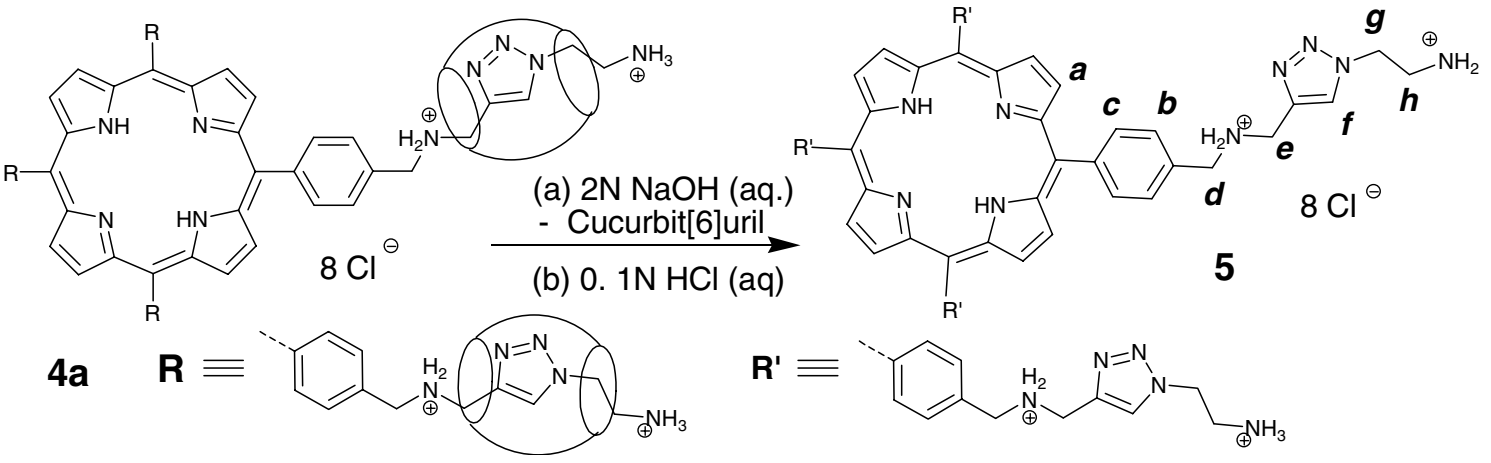

Scheme 3. Synthesis of model porphyrin $\mathbf{5}$.

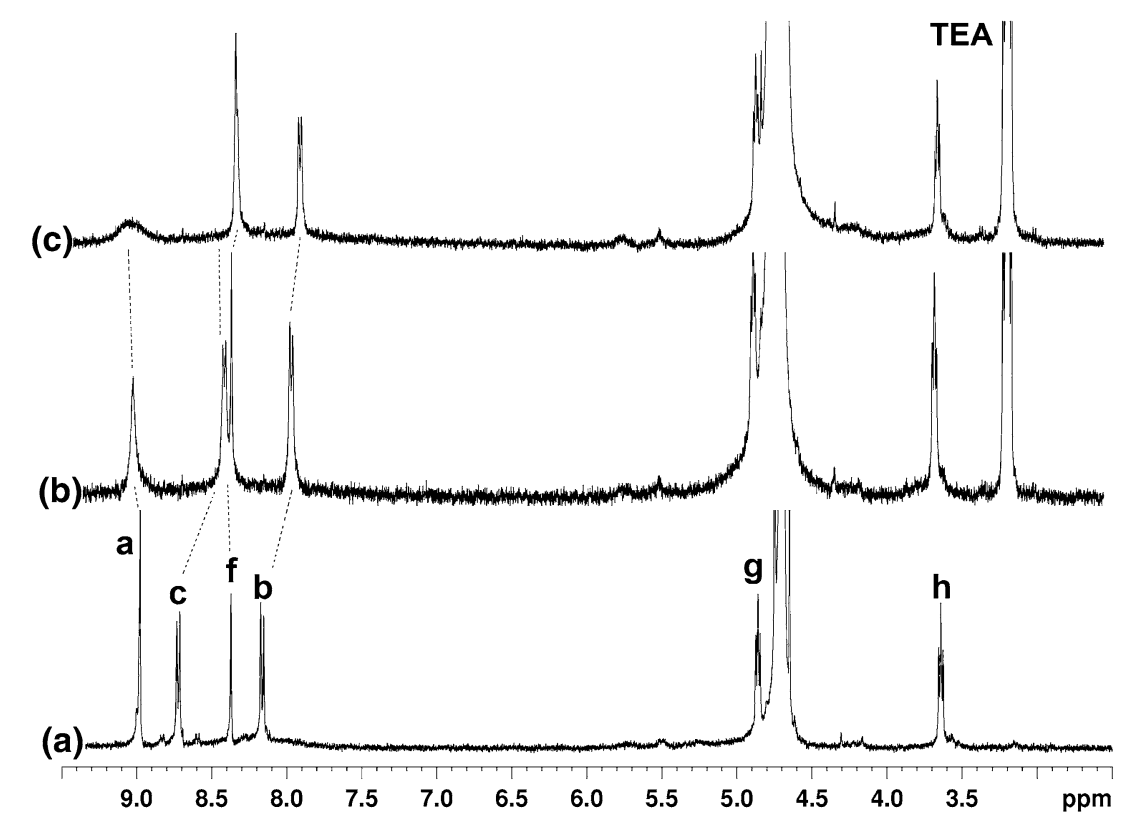

Figure 1. ${ }^{1} \mathrm{H}-\mathrm{NMR}$ spectra $\left(400 \mathrm{MHz}, \mathrm{D}_{2} \mathrm{O}, 25^{\circ} \mathrm{C}\right)$ of (a) Porphyrin 5 before addition of TEA, (b) After addition of TEA, $\mathrm{pH} \sim 6.5$, (c) $\mathrm{pH} \sim 7.0$.

nitrogens of porphyrin, but there is no change in the ${ }^{1} \mathrm{H}-$ NMR spectrum similar to that in Figure 2a. After adjusting the $\mathrm{pH}$ of the solution to 4.5 , the spectrum reveals broad signals for all of the $\mathbf{4 b}$ protons. The intensity of the threaded triazole proton signal at 6.6 decreases and a new small signal at $8.2 \mathrm{ppm}$ due to unthreaded triazole proton appears (Figure 2b) suggesting some degree of movement at $\mathbf{1}$. Furthermore, up to $\mathrm{pH} 7$ (Figure 2d, e) signals due to $\mathbf{1}$ are quite broad with some sharp spikes suggesting there is more than one environment for the protons of $\mathbf{1}$ due both to binding through ion-dipole interaction with protonated terminal nitrogens and to hydrophobic interaction. Additionally, the signal for $t$-butyl protons becomes broader and is shifted upfield appx. $0.1 \mathrm{ppm}$ suggesting partial movement of $\mathbf{1}$. The intensity of threaded triazole proton signal also gradually decreases and around $\mathrm{pH} 7$ (Figure 2e), it almost disappears. Moreover, at this $\mathrm{pH}$, signals due to protons $\mathbf{c}$ and $\mathbf{b}$ at 8.8 and $8.5 \mathrm{ppm}$ respectively disappear and new signals at 8.3 and $8.2 \mathrm{ppm}$ appear (Figure 2e). Up-field chemical shifts for the phenyl protons $\mathbf{c}(0.5 \mathrm{ppm})$ and $\mathbf{b}(0.3 \mathrm{ppm})$ indicate that these protons reside within the cavity of $\mathbf{1}$. This characteristic up-field shift is attributable to the shielding effect of 1 . On the other hand, the signal due to triazole proton $\mathbf{f}$ shifts down-field (ca. $1.7 \mathrm{ppm}$ ), suggesting that the triazole ring is not threaded by 1 . The signals due to protons $\mathbf{d}$ and $\mathbf{e}$ at 4.9 and $4.5 \mathrm{ppm}$ respectively disappear; probably they overlap with the peaks of water and $\mathbf{1}$ respectively. All these results indicate that deprotonation of benzylammonium ions is probably enough to cause 1 to shuttle from triazole site to benzyl site, despite the fact that there is still one iondipole interaction available with the $t$-butylammonium group to stabilize the complex between $\mathbf{1}$ and triazole group.

At $\mathrm{pH}$ 9, the signals due to the proton of $\mathbf{1}$ become sharper and the signal due to $t$-butyl protons not only becomes sharper but is also shifted upfield appx. $0.2 \mathrm{ppm}$ indicating the partial deprotonation of $t$-butylammonium ions (Figure 2f). Moreover, the signal due to $\beta$-pyrrole protons $\boldsymbol{a}$ of porphyrin becomes broader 

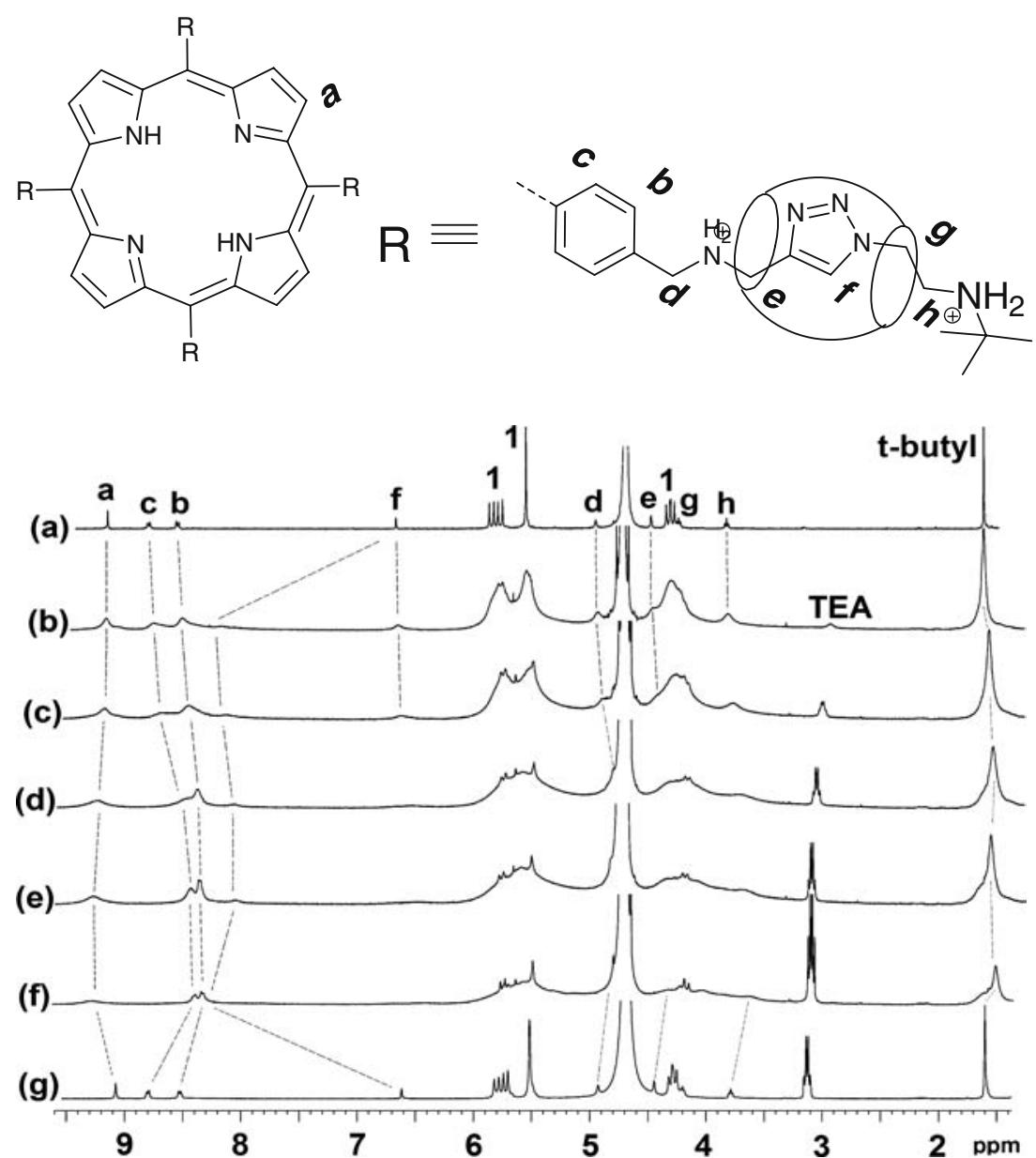

Figure 2. Comparison of the ${ }^{1} \mathrm{H}-\mathrm{NMR}$ spectra $\left(400 \mathrm{MHz}, \mathrm{D}_{2} \mathrm{O}, 25^{\circ} \mathrm{C}\right)$ of [5]rotaxane, $\mathbf{4 b}$ (a) before addition of TEA, state I, (b) after addition of TEA (pH 4.5), (c) $\mathrm{pH} 5.0$, (d) $\mathrm{pH} 5.5$, (e) $\mathrm{pH}$ 7, (f) $\mathrm{pH} \mathrm{9,} \mathrm{(g)} \mathrm{after} \mathrm{addition} \mathrm{of} \mathrm{aq.} \mathrm{HCl}$ to the base treated solution (pH 3.5), state I.

and is shifted downfield appx. 0.2 ppm indicating that $\mathbf{1}$ is localized over phenyl ring.

Upon addition of $\mathrm{HCl}$ (aq.) ( $\mathrm{pH} 3.5)$ to the base treated NMR sample, 1 moves to its initial location (Figure 1g), which is the triazole site (state I) and sharp chemical shifts due to triazole proton $\mathbf{f}$ and phenyl protons $\mathbf{b}$, and $\mathbf{c}$ reappear at $6.6,8.5$ and 8.8 respectively. Moreover, chemical shifts due to the protons of $\mathbf{1}$ and $t$-butyl become sharper.

The $\mathrm{pH}$-dependent $\mathrm{UV}-\mathrm{Vis}$ experiments were also carried out to observe the absorption spectral changes during switching processes. However, with the current results no significant changes were observed in the absorption properties of porphyrin core.

It should also be mentioned here the solubility behaviors of the porphyrin 5 and rotaxane $\mathbf{4 b}$. Treating the solution of $5(2.0 \mathrm{mM})$ in $\mathrm{D}_{2} \mathrm{O}$ with TEA at $\mathrm{pH}>7$ causes an immediate precipitation, in contrast, $4 \mathbf{b}$ remains soluble in water up to $\mathrm{pH} 12$ to a concentration of greater than $2.0 \mathrm{mM}$. This result reveals that model porphyrin $\mathbf{5}$ is clearly behaving differently than $\mathbf{4 b}$ and the presence of $\mathbf{1}$ has a significant impact on the solubility properties of porphyrin core.

In summary, we have reported the synthesis and characterization of [5]pseudorotaxane and [5]rotaxane based on cucurbit[6]uril as a macrocycle with a por- phyrin core. The preliminary results obtained through ${ }^{1} \mathrm{H}-\mathrm{NMR}$ spectroscopy suggest that [5]rotaxane $\mathbf{4 b}$ behaves like a $\mathrm{pH}$-driven switch. Currently, we are investigating the switching processes further both through detailed NMR measurements and by fluorescent spectroscopy.

\section{Experimental section}

\section{General}

All reagents and solvents were of the commercial reagent grade and used without further purification except where noted. Column chromatography was carried out using silica gel (Kieselgel 60, 0.063-0.200 mm). Thin layer chromatography (TLC) was performed on silica gel plates (Kieselgel 60 F254, $1 \mathrm{~mm}$ ).

Nuclear Magnetic Resonance (NMR) spectra were recorded on $400 \mathrm{MHz}$ NMR spectrometer. In all cases, samples were dissolved in $\mathrm{D}_{2} \mathrm{O}$ with DSS (3-(trimethyl silyl)-1-propanesulfonic acid), sodium salt as an external standard. Mass spectra were recorded in a reflection positive mode on a MALDI-TOF MS spectrometer and the samples were measured in 2,4,6-Trihydroxyacetophenone (5\% sol. in Methanol) as matrix. They were 
dissolved in $\mathrm{H}_{2} \mathrm{O}(2 \mathrm{mg} / \mathrm{ml}), 1: 1$ mixed with the matrix and $0.5 \mu \mathrm{l}$ of this mixture was add on the target.

Synthesis of Prop-2-ynyl-\{4-[10,15,20-Tris-(4-prop-2ynylaminomethyl-phenyl)-porphyrin-5-yl]-benzyl\}-amine tetrahydrochloride 3

$5,10,15,20$-Tetrakis ( $\alpha$-bromo- $p$-toly)porphyrin 2 (73 mg, $0.075 \mathrm{mmol}$ ) was dissolved in $\mathrm{CH}_{2} \mathrm{Cl}_{2}$. Excess propargylamine $(1.0 \mathrm{ml}, 15 \mathrm{mmol})$ was placed in a round-bottomed flask. The solution of $\mathbf{2}$ in $\mathrm{CH}_{2} \mathrm{Cl}_{2}$ was added dropwise to the propargylamine containing flask. The resulting reaction mixture was stirred at $\mathrm{rt}$ for $72 \mathrm{~h}$. The reaction was monitored by TLC $\left(\mathrm{CH}_{2} \mathrm{Cl}_{2}: \mathrm{MeOH}\right.$, $7: 1, \mathrm{v} / \mathrm{v})$. After the reaction was complete, aq. $\mathrm{NaOH}$ solution $(0.1 \mathrm{~N}, 10 \mathrm{ml})$ was added to the reaction mixture and the mixture was stirred for $1 \mathrm{~h}$ at $\mathrm{rt}$. Then $\mathrm{CH}_{2} \mathrm{Cl}_{2}(20 \mathrm{ml})$ was added and the dark red colored organic layer was separated from the aqueous layer; the solvent was removed under reduced pressure to yield purple colored solid residue which was purified through column chromatography using $\mathrm{CH}_{2} \mathrm{Cl}_{2}-\mathrm{MeOH}$ mixture $(10: 1, \mathrm{v} / \mathrm{v})$ as an eluent. The desired fractions were combined and the total volume was concentrated to about one third of the initial volume. Aq. solution of $\mathrm{HCl}(0.1 \mathrm{~N}, 5 \mathrm{ml})$ was added to this solution to convert freebase porphyrin into hydrochloride salt. The color changed from dark red to green. After the mixture was stirred at $\mathrm{rt}$ for $8 \mathrm{~h}$, the solvent was removed under reduced pressure and the resulting green solid residue was purified by recrystallization using water-acetone solvent mixture. Green powder was obtained and dried in the vacuum oven at $40{ }^{\circ} \mathrm{C}$ overnight.

Yield: $62 \mathrm{mg}(80 \%)$.

$\mathrm{mp}>300^{\circ} \mathrm{C}$ (decomp).

UV-Vis $\left(\mathrm{H}_{2} \mathrm{O}\right): \lambda_{\max }(\epsilon)=413 \mathrm{~nm}$ (578000), 518 (15000), 554 (8300), 585 (5700), 645 (4900)

Elemental Analysis of $\mathrm{C}_{60} \mathrm{H}_{54} \mathrm{Cl}_{4} \mathrm{~N}_{8} \cdot 3 \mathrm{H}_{2} \mathrm{O}$

Calc.: C, 66.54; H, 5.58; N, 10.34 Found: C, 66.44; $\mathrm{H}, 5.52 ; \mathrm{N}, 10.82$

${ }^{1} \mathrm{H}-\mathrm{NMR} \quad\left(400 \mathrm{MHz}, \quad \mathrm{D}_{2} \mathrm{O}\right): \quad \delta \quad 3.22 \quad(\mathrm{t}, \quad 8 \mathrm{H}$, $\left.{ }^{4} J_{\mathrm{HH}}=3.15 \mathrm{~Hz}, \mathbf{k}\right), 4.18\left(\mathrm{~d}, 8 \mathrm{H},{ }^{4} J_{\mathrm{HH}}=3.15 \mathrm{~Hz}, \mathbf{i}\right)$, $4.85(\mathrm{~s}, 8 \mathrm{H}, \mathbf{h}), 8.18\left(\mathrm{~d}, 8 \mathrm{H},{ }^{3} J_{\mathrm{HH}}=10.05 \mathrm{~Hz}, \mathbf{e}\right), 8.71$ $\left(\mathrm{d}, 8 \mathrm{H},{ }^{3} \mathrm{~J}_{\mathrm{HH}}=10.05 \mathrm{~Hz}, \mathbf{f}\right), 9.09(\mathrm{~s}, 8 \mathrm{H}, \mathrm{a})$.

${ }^{13} \mathrm{C}-\mathrm{NMR}\left(100 \mathrm{MHz}, \mathrm{D}_{2} \mathrm{O}\right.$, DSS): $\delta 36.3$ (i), (h), 50.0 (k), $73.5(\mathbf{j}), 79.2(\mathbf{h}), 122.9(\mathbf{g}), 130.6(\mathbf{e}), 130.8(\mathbf{c}), 133.3$ (f), 140.0 (e), 141.0 (b), 145.9 (a).

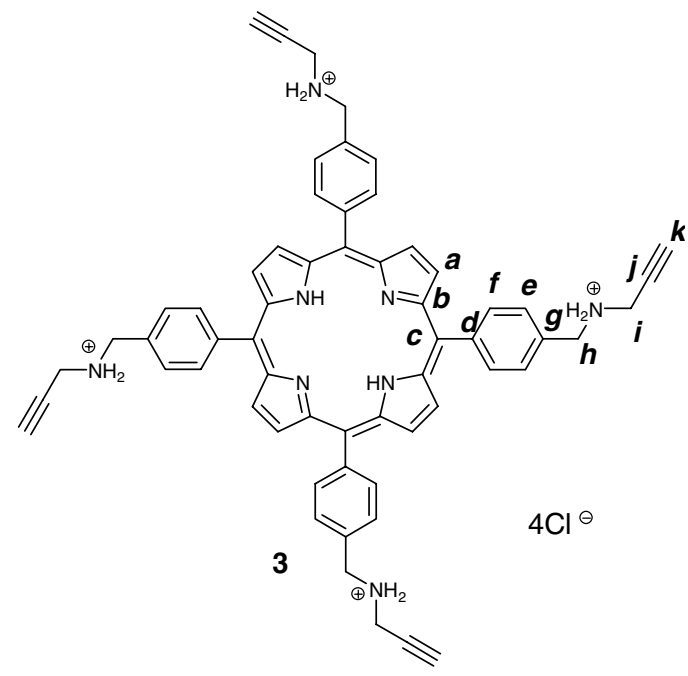

Synthesis of [5]rotaxane $\mathbf{4 b}$

Cucurbituril (110 mg, $0.11 \mathrm{mmol})$ was dissolved in $5 \mathrm{ml}$ of $6 \mathrm{~N} \mathrm{HCl}$ and the resulting solution was stirred for $1 / 2 \mathrm{~h}$. Porphyrin $2(26 \mathrm{mg}, 0.025 \mathrm{mmol})$ followed by tert-butylazidoethylamine $(22 \mathrm{mg}, 0.12 \mathrm{mmol})$ were added with vigorous stirring and the resulting greencoloured clear solution was stirred at $\mathrm{rt}$ for $48 \mathrm{~h}$. The solvent was removed under reduced pressure to yield a green film, which was suspended in $\mathrm{MeOH}(3 \mathrm{ml})$ at $\mathrm{rt}$ and stirred for $3 \mathrm{~h}$ to remove unreacted monomers. The solid residue was collected by filtration and washed with $\mathrm{MeOH}(3 \mathrm{ml})$ followed by acetone $(5 \mathrm{ml})$. To remove excess cucurbituril, the precipitate was dissolved in warm water $(5 \mathrm{ml})$ at $\sim 50{ }^{\circ} \mathrm{C}$ and stirred for $1 \mathrm{~h}$. Undissolved particles were removed by micro filtration using membrane of $0.45 \mu \mathrm{m}$ pore size. Removal of the solvent under reduced pressure yielded green colored powder, which was further recrystalized using a water-acetone mixture to produce green crystalline solid.

Yield: $122 \mathrm{mg}(85 \%)$.

$\mathrm{mp}>300{ }^{\circ} \mathrm{C}$ (decomp).

UV-Vis $\left(\mathrm{H}_{2} \mathrm{O}\right): \lambda_{\max }: 415 \mathrm{~nm}(366000), 518$ (13600), 555 (8300), 583 (6200), 637 (4200)

MALDI-TOF (m/z): $5476[(4 \mathrm{~b}-8 \mathrm{HCl})+\mathrm{H}+\mathrm{K}]^{+}$

Elemental Analysis of $\mathrm{C}_{228} \mathrm{H}_{258} \mathrm{Cl}_{8} \mathrm{~N}_{120} \mathrm{O}_{48} \times 30 \mathrm{H}_{2} \mathrm{O}$

Calc.: C, 43.41; H, 5.19; N, 26.64; Found: C, 43.52; $\mathrm{H}, 5.41 ; \mathrm{N}, 26.71$

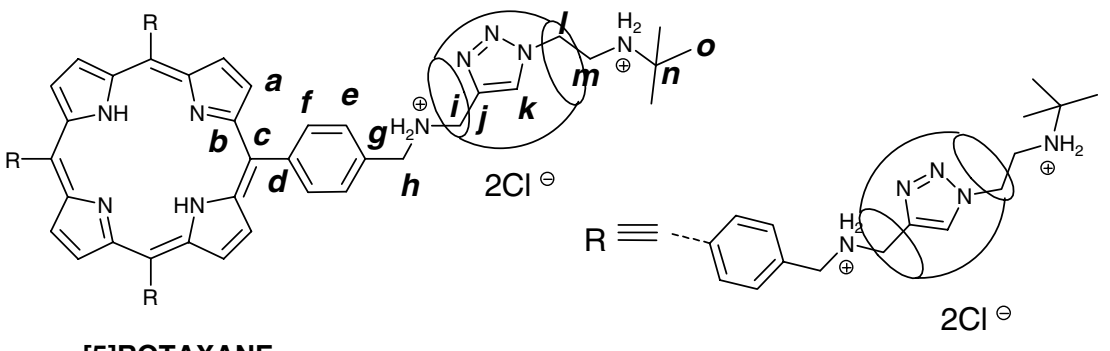

[5]ROTAXANE 


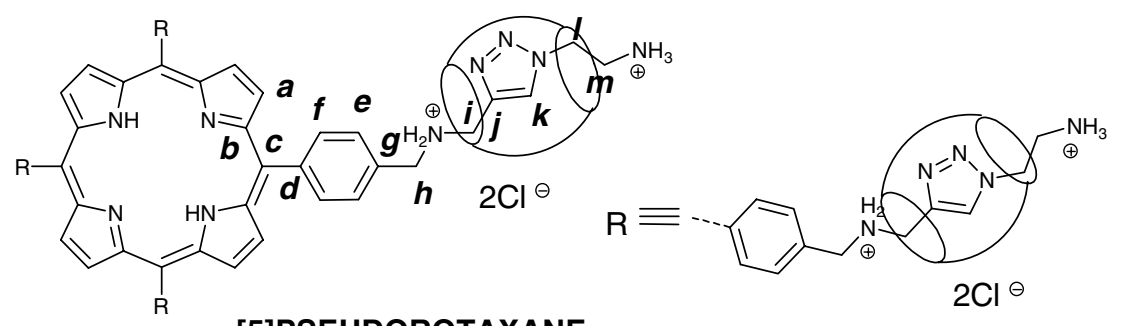

[5]PSEUDOROTAXANE

${ }^{1} \mathrm{H}-\mathrm{NMR}\left(500 \mathrm{MHz}, \mathrm{D}_{2} \mathrm{O}\right): \delta 1.61(\mathrm{~s}, 36 \mathrm{H}, \mathbf{o}), 3.81(\mathrm{t}$, $\left.8 \mathrm{H},{ }^{3} J_{\mathrm{HH}}=7.95 \mathrm{~Hz}, \mathbf{m}\right), 4.13\left(\mathrm{t}, 8 \mathrm{H},{ }^{3} J_{\mathrm{HH}}=8.15 \mathrm{~Hz}\right.$, I), $4.25(48 \mathrm{H}, \mathbf{Q Q}), 4.39$ (s, 8H, i), $4.86(\mathrm{~s}, 8 \mathrm{H}, \mathbf{h}), 5.52$ (48H, QQ), $5.75(48 \mathrm{H}, \mathrm{QQ}), 6.62(\mathrm{~s}, 4 \mathrm{H}, \mathbf{k}), 8.52(\mathrm{~d}, 8 \mathrm{H}$, $\left.{ }^{3} J_{\mathrm{HH}}=9.9 \mathrm{~Hz}, \mathbf{e}\right), 8.79\left(\mathrm{~d}, 8 \mathrm{H},{ }^{3} J_{\mathrm{HH}}=10.1 \mathrm{~Hz}, \mathbf{f}\right)$, 9.09 (s, 8H, a).

${ }^{13} \mathrm{C}-\mathrm{NMR}\left(125 \mathrm{MHz}, \mathrm{D}_{2} \mathrm{O}, \mathrm{DSS}\right): \delta 25.2$ (o), 40.0 (m), 42.5 (l), 47.5 (h), 51.3 (QQ), 51.5(QQ), 52.5 (n), 70.2 (QQ), 120.9 (k), 122.5 (g), 129.9 (f), 130.8 (c), 132.7 (d), 138.8 (e), 138.9 (j), 140.1 (b), 145.1 (a), 156.3 (QQ), 156.7 (QQ).

\section{Synthesis of [5]pseudorotaxanes $\mathbf{4 a}$}

The same procedure as [5]rotaxane.

Yield: $75 \%$.

$\mathrm{mp}>300{ }^{\circ} \mathrm{C}$ (decomp).

UV-Vis $\left(\mathrm{H}_{2} \mathrm{O}\right): \lambda_{\max }: 414 \mathrm{~nm}(380000), 518$ (13900), 555 (9100), 583 (6500), 637 (4700).
Synthesis of 2-\{4-[(4-\{10,15,20-Tris-[4-(\{[1-(2-aminoethyl)-1H-[1,2,3]triazol-4-ylmethyl]-amino\}-methyl)phenyl]-porphyrin-5-yl\}-benzylamino)-methyl]-

[1,2,3]triazol-1-yl $\}$-ethylamine octahydrochloride 5

4a (100 mg, $0.018 \mathrm{mmol})$ was dissolved in water $(5 \mathrm{ml})$ and $1 \mathrm{ml}$ of $2 \mathrm{~N}$ aq. $\mathrm{NaOH}$ solution was added to this solution. Upon addition of $\mathrm{NaOH}$ solution, 5 has started to precipitate out. The mixture was stirred for $1 \mathrm{~h}$. Then precipitates were collected by centrifugation and wash with water several times. Subsequently $5 \mathrm{ml}$ of $0.1 \mathrm{~N} \mathrm{HCl}$ solution was added to dissolve the precipitates. The resulting solution was stirred for $1 \mathrm{~h}$ and then the water was removed under reduced pressure to yield green colored solid residue.

Yield: $25 \mathrm{mg}(86 \%)$.

$\mathrm{mp:} 300{ }^{\circ} \mathrm{C}$ (decomp).

$\mathrm{UV}-\mathrm{Vis}\left(\mathrm{H}_{2} \mathrm{O}\right): \lambda_{\max }: 414 \mathrm{~nm}$ (280000), 519 (116900), 556 (8500), 584 (5500), 644 (4200).

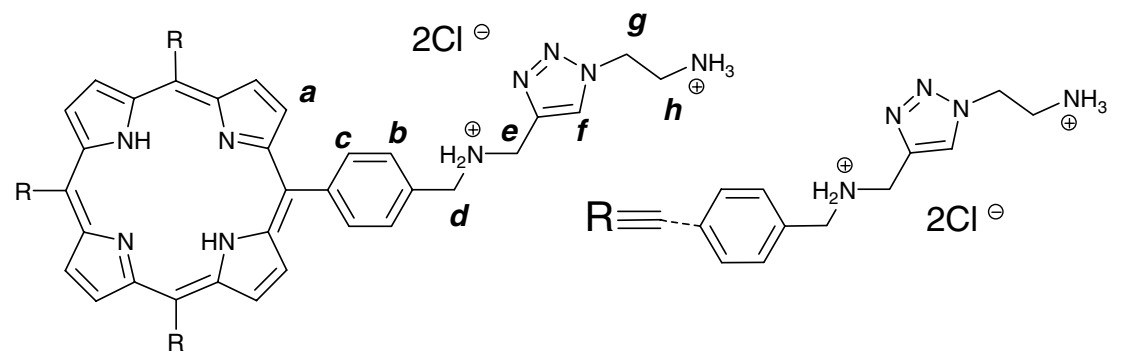

MALDI-TOF $(\mathrm{m} / \mathrm{z}): 5217[(4 \mathrm{a}-8 \mathrm{Cl})-3 \mathrm{H}]^{+}, 4221$ $[(4 a-8 \mathrm{Cl}-2 \mathrm{H})-\mathrm{CB} 6]^{+}$.

Elemental Analysis of $\mathrm{C}_{212} \mathrm{H}_{226} \mathrm{Cl}_{8} \mathrm{~N}_{120} \mathrm{O}_{48} \times 5 \mathrm{H}_{2} \mathrm{O}$

Calc.: C, 45.49; H, 4.25; N, 30.03; Found: C, 45.53; $\mathrm{H}, 4.54 ; \mathrm{N}, 29.05$

${ }^{1} \mathrm{H}-\mathrm{NMR} \quad\left(400 \mathrm{MHz}, \quad \mathrm{D}_{2} \mathrm{O}\right): \quad 3.56 \quad(\mathrm{t}, \quad 8 \mathrm{H}$, $\left.{ }^{3} J_{\mathrm{HH}}=5.93 \mathrm{~Hz}, \mathbf{m}\right), 4.19\left(\mathrm{t}, 8 \mathrm{H},{ }^{3} J_{\mathrm{HH}}=5.95 \mathrm{~Hz}, \mathrm{l}\right)$, 4.25 (48 H, CB6), 4.48 (s, 8H, i), 4.93 (s, 8H, h), 5.51 $(48 \mathrm{H}, \mathrm{CB} 6), 5.76(48 \mathrm{H}, \mathrm{CB} 6), 6.63(\mathrm{~s}, 4 \mathrm{H}, \mathbf{k}), 8.52(\mathrm{~d}$, $\left.8 \mathrm{H},{ }^{3} J_{\mathrm{HH}}=7.75 \mathrm{~Hz}, \mathbf{e}\right), 8.80\left(\mathrm{~d}, 8 \mathrm{H},{ }^{3} J_{\mathrm{HH}}=7.69 \mathrm{~Hz}\right.$, f), $9.08(\mathrm{~s}, 8 \mathrm{H}, \mathrm{a})$.

${ }^{13} \mathrm{C}-\mathrm{NMR}\left(100 \mathrm{MHz}, \mathrm{D}_{2} \mathrm{O}\right): \delta 38.4$ (m), 42.7 (i), 47.4 (h), 51.6 (CB6), 51.8 (CB6) 70.7 (CB6), 121.5 (k), 123.5 (c), 130.8 (f), 131.6 (e), 133.6 (g), 138.9 (d), 139.9 (b), 141.1 (j), 146.1 (a), 157.2 (CB6), 157.7 (CB6).
MALDI-TOF $(\mathrm{m} / \mathrm{z}): 1227.58(5-8 \mathrm{HCl}), 1228.58$ $[(5-8 \mathrm{HCl})+\mathrm{H}], 1229.58[(5-8 \mathrm{HCl})+2 \mathrm{H}]$.

${ }^{1} \mathrm{H}-\mathrm{NMR} \quad\left(400 \mathrm{MHz}, \quad \mathrm{D}_{2} \mathrm{O}\right): \quad 3.56 \quad(\mathrm{t}, \quad 8 \mathrm{H}$, $\left.{ }^{3} J_{\mathrm{HH}}=5.93 \mathrm{~Hz}, \mathbf{h}\right), 4.85\left(\mathrm{t}, 8 \mathrm{H},{ }^{3} J_{\mathrm{HH}}=5.95 \mathrm{~Hz}, \mathbf{g}\right)$, $8.14\left(\mathrm{~d}, 8 \mathrm{H},{ }^{3} J_{\mathrm{HH}}=7.75 \mathrm{~Hz}, \mathbf{b}\right), 8.36(\mathrm{~s}, 4 \mathrm{H}, \mathbf{f}), 8.71(\mathrm{~d}$, $\left.8 \mathrm{H},{ }^{3} J_{\mathrm{HH}}=7.69 \mathrm{~Hz}, \mathbf{c}\right), 8.95(\mathrm{~s}, 8 \mathrm{H}, \mathrm{a})$.

Note: The resonances due to protons $\mathrm{d}$ and e overlap with $\mathrm{D}_{2} \mathrm{O}$ signal.

\section{${ }^{1} H$-NMR experiment of switching process of $\mathbf{4 b}$}

$4 \mathbf{b}(5 \mathrm{mg})$ was dissolved in $\mathrm{D}_{2} \mathrm{O}(0.5 \mathrm{ml})$ and the resulting solution was transferred to an NMR tube. ${ }^{1} \mathrm{H}-\mathrm{NMR}$ spectrum was recorded. To this sample, $1 \mu \mathrm{l}$ of $2 \mathrm{~N}$ TEA was added subsequently its ${ }^{1} \mathrm{H}-\mathrm{NMR}$ spectrum was 
recorded. This process was repeated until the $\mathrm{pH}$ of solution reached to 9 . To switching back to state I, $5 \mu \mathrm{l}$ of $0.1 \mathrm{~N} \mathrm{HCl}$ was added to base treated sample. The process was repeated until the $\mathrm{pH}$ reached to 3.5.

\section{Acknowledgements}

This research was supported by the Scientific and Technical Research Council of Turkey (TUBITAK, Grant No: MISAG 260) and by a Bilkent University Faculty Development Grant. The authors thank the Chemistry Department of Hacettepe University and the TUBITAK Analysis Centre for the NMR, and Dr. M. Katterle (Potsdam University) and Prof. B. Salih (Chemistry Department of Hacettepe University) for MALDI-TOF measurements.

\section{Electronic supplementary material}

${ }^{1} \mathrm{H},{ }^{13} \mathrm{C}-\mathrm{NMR}$ and MALDI-TOF MS spectra of $\mathbf{3}, \mathbf{4 a}$, 4b and 5.

\section{References}

1. (a) On molecular machine and motors: Special issue of Account of Chemical Research, 2001, 6, guest-edited by Stoddart, J.F; (b) J.W. Steed and J.L. Atwood: Supramolecular Chemistry, John Wiley and Sons, Ltd, (2000).

2. (a) S.A. Nepogodiev and J.F. Stoddart: Chem. Rev. 98, 1959 (1998); (b) Molecular Catenanes, Rotaxanes, and Knots, ed. J.-P. Sauvage, C.O. Dietrich-Buchecker, Wiely-VCH, Weinheim (1999).
3. J.D. Badjic, V. Balzani, A. Credi, S. Silvi, and J.F. Stoddart: Science 303, 1847 (2004)

4. (a) W.L. Mock: In F. Vogtle (ed.), Comprehensive Supramolecular Chemistry, Vol. 2, Pergamon, Oxford (1996), 477; (b) K. Kim: Chem. Soc. Rev. 31, 96 (2002); (c) J. Lagona, P. Mukhopadhyay, S. Chakrabarti, and L. Isaacs: Angew. Chem. Int. Ed. 44, 4844 (2005).

5. D. Tuncel and J.H.G. Steinke: Macromolecules 37, 288 (2004).

6. (a) J.W. Lee, K. Kim, and K. Kim: Chem. Commun. 1042 (2001); (b) S.I. Jun, J.W. Lee, S. Sakamoto, K. Yamaguchi, and K. Kim: Tetrahedron Lett. 41, 471 (2000).

7. (a) M.-S. Choi, T. Yamazaki, I. Yamazaki, and T. Aida: Angew. Chem. Int. Ed. 43, 150 (2004); (b) A.K. Burrell, D.L. Officer, P.G. Plieger, and D.C. Reid: Chem. Rev. 101, 2751 (2001).

8. (a) L.M. Scolaro, A. Romeo, and R.F. Pasternack: J. Am. Chem. Soc. 126, 7178 (2004); (b) C.N. Lunardi and A.C. Tedesco: Curr. Org. Chem. 9, 813 (2005).

9. (a) G. Moschetto, R. Lauceri, F.G. Gulino, D. Sciotto, and R. Purrello: J. Am. Chem. Soc. 124, 14536 (2002); (b) R.G.E. Coumans, J.A.A.W. Elemans, P. Thordarson, R.J.M. Nolte, and E. Rowan: Angew. Chem. Int. Ed. 42, 650 (2003); (c) K. Kano, R. Nishiyabu, T. Yamazaki, and I. Yamazaki: J. Am. Chem. Soc. 125, 10625 (2003); (d) D. Kuciauskas, P.A. Liddell, S. Lin, T.E. Johnson, S.J. Weghorn, J.S. Lindsey, A.L. Moore, and D. Gust: J. Am. Chem. Soc. 121, 8604 (1999); (e) D.L. Dick, T.V.S. Rao, D. Sukumaran, and D.S. Lawrence: J. Am. Chem. Soc. 114, 2664 (1992); (f) K. Kano, R. Nishiyabu, T. Asada, and Y. Kuroda: J. Am. Chem. Soc. 124, 9937 (2002); (g) K. Kano, R. Nishiyabu, and R. Doi: J. Org. Chem. 70, 3667 (2005).

10. L. Wen, M. Li, and J.B. Schlenoff: J. Am. Chem. Soc. 119, 7726 (1997).

11. (a) W.L. Mock and N.-Y. Shih: J. Org. Chem. 51, 4440 (1986); (b) W.L. Mock and N.-Y. Shih: J. Am. Chem. Soc. 110, 4706 (1988); (c) W.A. Freeman: Acta Crystallgr., Sect. B B40, 382 (1984).

12. At $\mathrm{pH}<4, \mathrm{UV}-\mathrm{Vis}$ spectrum reveals one absorption peak due to Soret Band at $432 \mathrm{~nm}$ and two absorption bands due to $\mathrm{Q}$ band at 593 and $647 \mathrm{~nm}$, whereas at $\mathrm{pH}>4$ the Soret Band appears at $414 \mathrm{~nm}$ along with four bands for the Q band at 515, 553, 588 and $637 \mathrm{~nm}$. 